\title{
Energia total de ruptura: um teste biomecânico para avaliação de material biológico com propriedade viscoelástica não linear ${ }^{1}$
}

\author{
Total energy of rupture: a biomechanical test to evaluate non-linear viscoelastic biological \\ material
}

\author{
Feng Chung Wu ${ }^{2}$, Huei Diana Lee ${ }^{3}$, Renato Bobsin Machado ${ }^{4}$, Sérgio Dalmás ${ }^{5}$, Cláudio Saddy Rodrigues Coy ${ }^{6}$, Juvenal \\ Ricardo Navarro Góes ${ }^{7}$, João José Fagundes ${ }^{6}$
}

1. Trabalho realizado no Núcleo de Medicina e Cirurgia Experimental - Disciplina de Moléstia do Aparelho Digestivo do Departamento de Cirurgia / D.M.A.D. Serviço de Coloproctologia da Faculdade de Ciências Médicas da UNICAMP e Laboratório de Bioinformática da Universidade Estadual do Oeste do Paraná - LABI-UNIOESTE / Foz do Iguaçu.

2. Pesquisador e aluno de pós-doutorado - Departamento de Cirurgia - Serviço de Coloproctologia da Faculdade de Ciências Médicas da UNICAMP e Coordenador da área médica do LABI-UNIOESTE / Foz do Iguaçu.

3. Professora do Centro de Engenharia e Ciências Exatas e Coordenadora geral do LABI-UNIOESTE / Foz do Iguaçu. Doutoranda na área de Inteligência Computacional pela ICMC-USP / São Carlos.

4. Professor do Centro de Engenharia e Ciências Exatas e Coordenador da área de informática do LABI-UNIOESTE / Foz do Iguaçu. Mestrando na área de Sistemas Distribuídos pela PGCC - Universidade Federal de Santa Catarina (UFSC).

5. Professor do Centro de Engenharia e Ciências Exatas e pesquisador do LABI-UNIOESTE / Foz do Iguaçu. Mestre em Engenharia Mecânica pela UFSC.

6. Professor Doutor do Departamento de Cirurgia - D.M.A.D. Serviço de Coloproctologia da UNICAMP.

7. Professor Associado e Chefe do Departamento de Cirurgia da Faculdade de Ciências Médicas da UNICAMP.

\section{RESUMO}

Objetivo: Apresentação do teste biomecânico Energia Total de Ruptura para o estudo da resistência intrínseca de material biológico com propriedade viscoelástica não-linear representado neste trabalho por segmento íntegro de cólon descendente de rato. Métodos: Implementação do teste biomecânico Energia Total de Ruptura e do Sistema de Aquisição e Análise de dados Biomecânicos - SABI 2.0. Para esse fim, foram utilizados conceitos físico-mecânicos, computacionais e biomecânicos e como corpos de teste, 15 espécimes de cólon descendente de ratos. Resultados: O teste biomecânico Energia Total de Ruptura permitiu o cálculo da energia total acumulada necessária para promover a ruptura dos corpos de prova durante os ensaios mecânicos. Por meio da automatização e gerenciamento da aquisição e análise dos dados capturados foi possível a geração de gráficos e relatórios descritivos e estatísticos. Conclusão: Fundamentado em conceitos físico-mecânicos, computacionais e biomecânicos, o teste Energia Total de Ruptura pôde proporcionar análise matemática do comportamento dos segmentos de cólon descendente de ratos durante os ensaios, demonstrando ser um possível método de medição da resistência intrínseca desse material biológico com propriedade viscoelástica não-linear.

Descritores: Biomecânica. Cólon. Cicatrização de feridas. Experimentção Animal.

\begin{abstract}
Purpose: Presentation of the Total Energy of Rupture biomechanical test to evaluate the intrinsic resistance of the rat's left colon which presents a non-linear viscoelastic property. Methods: Implementation of Total Energy of Rupture test (ETR) and the Biomechanical Data Acquisition and Analysis System (SABI 2.0) based on physic-mechanical, computational and biomechanical concepts. Fifteen specimens of Wistar adults rat's left colon where considered for experiments. Results: Using the TER biomechanical test it was possible calculate the accumulated total energy necessary to promote the specimens rupture during the mechanical trial. It was also possible to generate descriptive and statistics reports and graphics through the data acquisition and analysis automatization and management. Conclusion: Based on physic-mechanical, computational and biomechanical concepts, the Total Energy of Rupture test provides mathematical analysis of the rat's left colon segment behaviour during the experiments, demonstrating to be a possible method to measure the intrinsic resistance of this biological material presenting non-linear viscoelastic property.
\end{abstract}

Key words: Biomechanics. Colon. Wound healing. Animal Experimentation 


\section{Introdução}

A resistência mecânica intrínseca da parede do cólon está vinculada com a sua segurança, pois a quebra da integridade dessa estrutura repercute diretamente nos índices de morbidade e mortalidade ${ }^{1,2}$.

Modelos experimentais fundamentados em conceitos físico-mecânicos têm sido amplamente utilizados com o intuito de avaliar a resistência da parede intestinal com presença ou não de anastomose. Para isso, aplicam-se ensaios uniaxiais como pressão de explosão ${ }^{3}$, força de ruptura à tração ${ }^{4}$ e tensão de ruptura $^{3}$ e biaxiais, por exemplo tensão resultante final de ruptura à tração ${ }^{5}$. Esses modelos analisam um ou dois atributos no momento crítico de ruptura e apesar de serem bastante usados, os resultados obtidos por meio desses testes biomecânicos representam parcialmente o comportamento do tecido biológico sob imposição de uma força externa e variável com o tempo ${ }^{3,6,7}$. Em virtude disso, propôs-se neste trabalho o teste biomecânico Energia Total de Ruptura (ETR), baseado no Princípio Universal de Conservação da Energia. Esse teste tem como finalidade avaliar, matematicamente, o comportamento do cólon descendente de rato o qual apresenta propriedade viscoelástica não-linear.

\section{Métodos}

Este trabalho foi aprovado pela Comissão de Ética na Experimentação Animal CEEA-IB-Unicamp, segundo os princípios éticos adotados pelo Colégio Brasileiro de Experimentação Animal - COBEA (Protocolo nº 589-1). Foram utilizados no experimento, como corpos de prova, cólons descendentes de 15 ratos machos provenientes do Centro de Bioterismo da Unicamp (CEMIB/Unicamp), linhagem Wistar (Rattus norvegicus albinus), peso variando de 300 a 350 gramas, idade aproximada de 120 dias e criados sob condições ambientais e alimentares semelhantes. A eutanásia foi realizada dose letal de pentobarbital sódico 3\% (Hypnol-Fontoverter ${ }^{\circledR}$ ) injetada na veia caudal. Após esse procedimento, a cavidade abdominal era aberta por incisão de quatro centímetros e retirado, de cada animal, quatro centímetros de cólon descendente a partir da reflexão peritoneal. Esses espécimes, antes de serem submetidos ao teste biomecânico ETR, eram submergidos em solução contendo cloridrato de papaverina (250 $\mathrm{mg} /$ litro) a $37^{\circ} \mathrm{C}$. Após 30 minutos de imersão, o segmento de alça era retirado. A extremidade proximal desse segmento foi atada a um canhão de cateter de "teflon" $n^{\circ} 18$ com a luz aberta e a extremidade distal atada a outro canhão de cateter de "teflon" $\mathrm{n}^{\mathrm{o}} 18 \mathrm{com}$ a luz vedada e fixada em corrente. A região de alça submetida à tração apresentava $1,5 \mathrm{~cm}$ de extensão, valor esse determinado com o auxílio de paquímetro (Figura 1, a-c).

(c)

$\underset{1,5 \mathrm{~cm}-1}{\cos \times X}$

FIGURA 1 - Representação esquemática: (a) segmento de cólon descendente, (b) canhão $\mathrm{n}^{\mathrm{o}} 18 \mathrm{com}$ luz aberta e (c) canhão $\mathrm{n}^{\circ} 18$ com luz vedada e fixada em corrente.
Após esses procedimentos, o espécime com as extremidades atadas aos respectivos canhões foi posicionado para a realização do teste biomecânico ETR (Figura 2, d).

$\mathrm{O}$ teste biomecânico ETR foi constituído pelos seguintes componentes (Figuras 2 e 3 ):

* Aplicativo SABI 2.0-Sistema de Aquisição e Análise de Dados Biomecânicos (Figura 2, m);

* Sistema de tração da bomba de infusão B.Braun / Modelo 871.012 (Figura 2, a);

* Gancho de aço inoxidável (Figura 2, b);

* Canhão de cateter endovenoso de "teflon" no 18 com luz vedada e fixada em sistema de corrente (Figura 2, c);

* Canhão de cateter endovenoso de "teflon" n' 18 com luz aberta (Figura 2, e);

* Torneira de tripla-via com a extremidade fixada em um sistema de corrente (Figura 2, f);

* Balança de precisão (Mettler-Toledo / Modelo SB8000) (Figura 2, g)

* Célula de carga da balança de precisão (MettlerToledo / Modelo SB8000) (Figura 2, h);

* Alavanca de conexão da célula de carga da balança com o sistema de tração (Figura 2, i);

* Saída serial da balança de precisão (RS232) (Figura $2, \mathrm{j})$;

* Cabo de comunicação serial (Figura 2, 1);

* Microcomputador PC padrão com canal de comunicação serial (Figura 2, m);

* Cateter de polietileno (P.E. 80) - 50 centímetros de comprimento (Figura 2, n);

* Seringa de plástico - Nipro $(10 \mathrm{ml})$ posicionada no transdutor do polígrafo (Figura 2, o); e

* Polígrafo Siemens-Elema / Modelo 804 Mingograft (Figura 2, p).

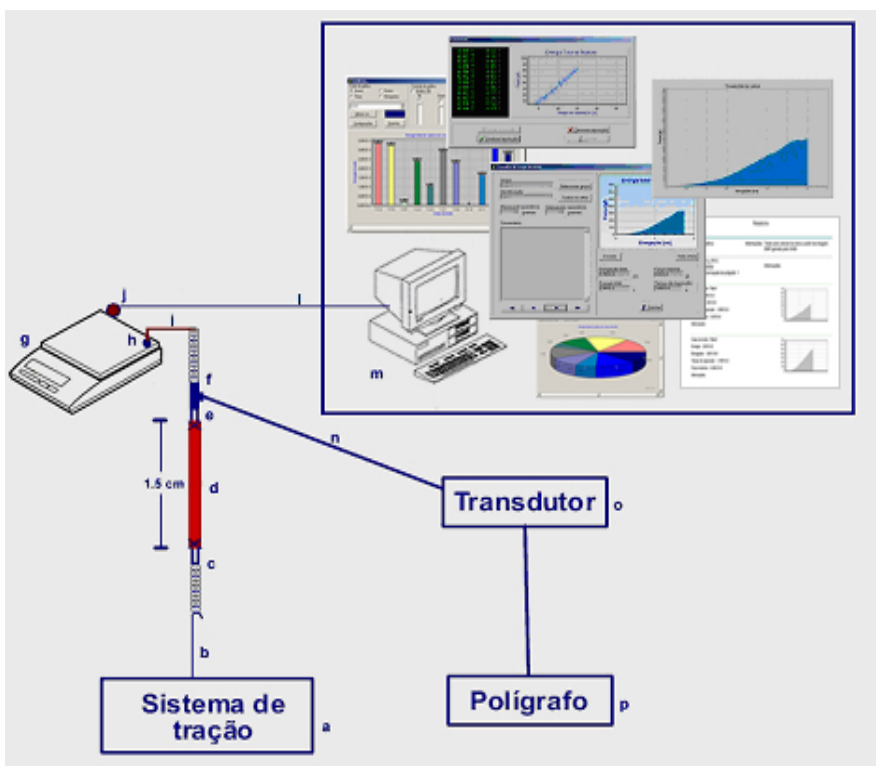

FIGURA 2 - Representação esquemática do teste biomecânico ETR 
O SABI 2.0 - Sistema de Aquisição e Análise de Dados Biomecânicos foi desenvolvido em parceria entre o Serviço de Coloproctologia da Universidade Estadual de Campinas e o Laboratório de Bioinformática da Universidade Estadual do Oeste do Paraná - campus Foz do Iguaçu. A implementação desse sistema baseou-se nos conceitos da Engenharia de Software utilizando o paradigma orientado ao objeto e com isso, requisitos fundamentais como leiaute, interface homemmáquina, armazenamento, recuperação e integridade dos dados foram levados em consideração durante o desenvolvimento.

Esse aplicativo constitui-se de dois subsistemas. O primeiro é responsável pela automatização da aquisição de dados por meio de comunicação serial via RS232 e o segundo pela interpretação e análise dos dados adquiridos durante os ensaios biomecânicos. Esses dados gerados pela célula de carga eram, em tempo real, delineados na tela do computador por uma curva pertencente à função Força $x$ Tempo. Após o término da aquisição, essa função era convertida, automaticamente, à função Força x Elongação, já que a velocidade de tração (um centímetro por minuto) foi constante durante todo o ensaio. Aplicando-se o método de integração numérica Regra do Trapézio, o SABI 2.0 foi capaz de determinar a área sob essa curva $^{8}$ (Figura 4). O valor obtido dessa área representou a energia total acumulada (ETR) para promover o rompimento do espécime sob teste ${ }^{9}$. Além dessas funções, foram implementados no SABI 2.0 requisitos relacionados à segurança do uso do sistema e geração de relatórios por meio do processo de Gerenciamento de Bancos de Dados. As funcionalidades de segurança consistiram na implementação do cadastramento de usuário por meio da identificação de nome, senha e acesso restrito aos dados de cada usuário cadastrado. Os relatórios gerados pelo aplicativo descreviam, em vários níveis de detalhes, todas as informações relacionadas aos grupos, subgrupos e corpos de teste. Essas informações podiam ser visíveis por meio de diversos tipos de gráficos e geradas em forma de arquivos. Essa última função permite que as informações sejam inseridas, diretamente, em aplicativos com a finalidade de realização de testes estatísticos.

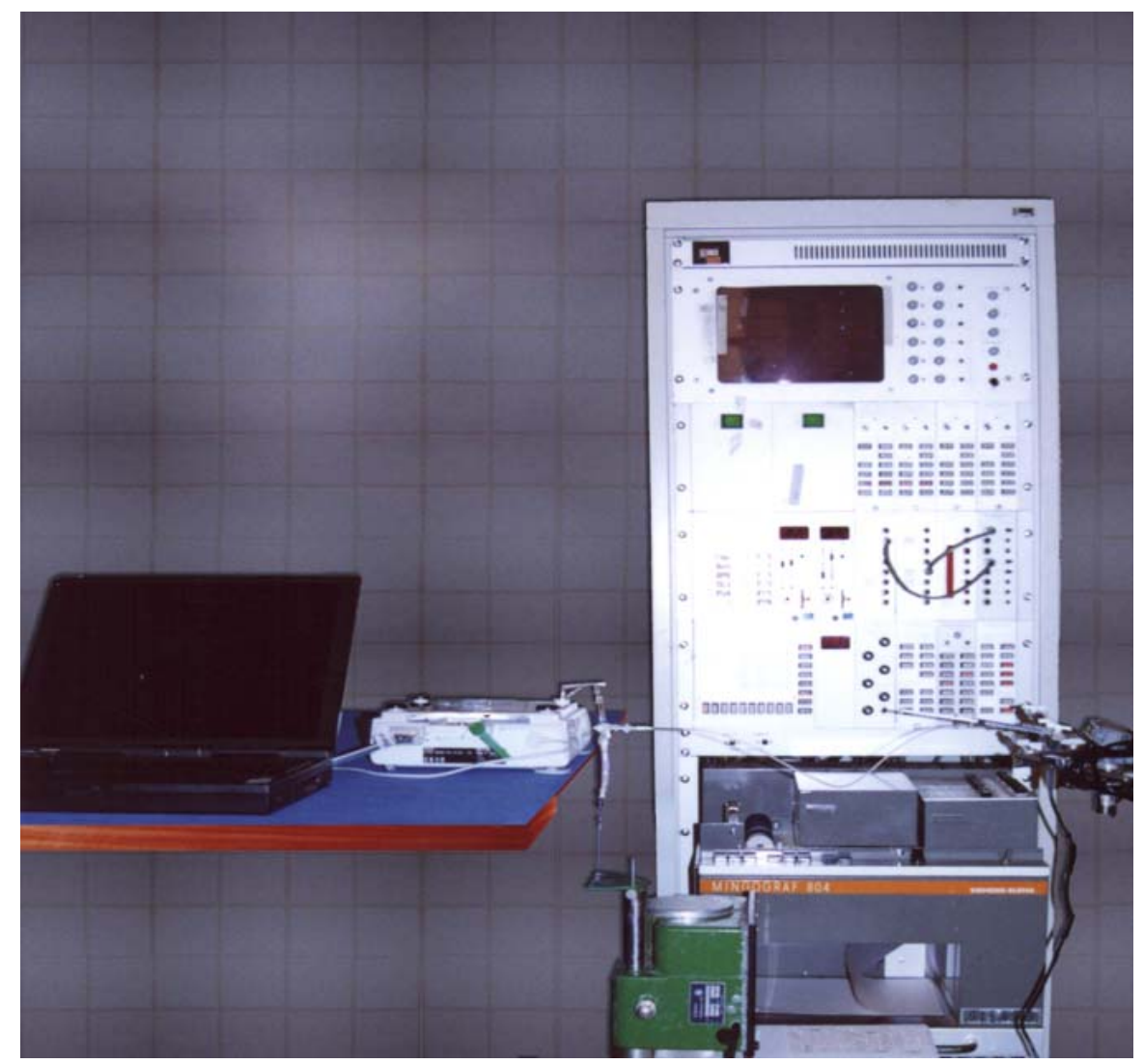

FIGURA 3 - Componentes pertencentes ao teste biomecânico ETR 

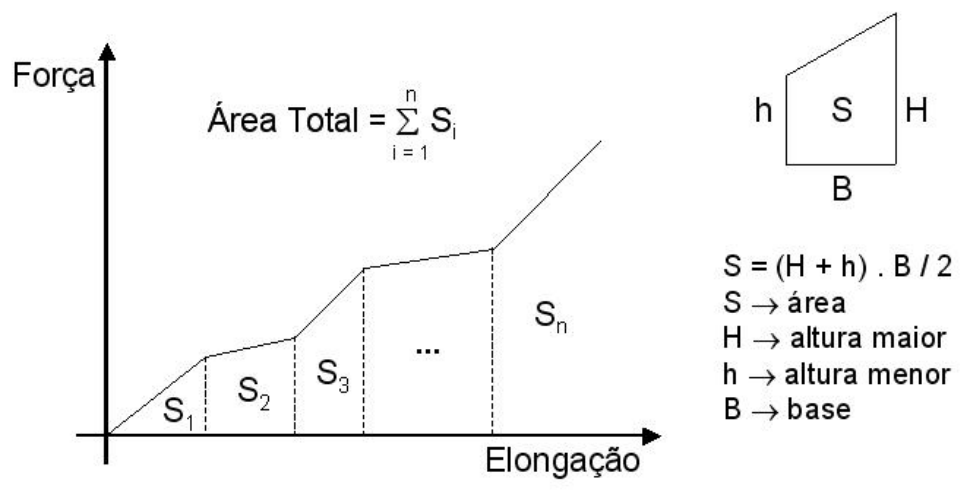

$\mathrm{S} \rightarrow$ área

$\mathrm{H} \rightarrow$ altura maior

$\mathrm{h} \rightarrow$ altura menor

$\mathrm{B} \rightarrow$ base

FIGURA 4 - Definição da Regra do Trapézio na integração numérica

Os componentes pertencentes ao teste ETR mantiveram as mesmas proporções de localização e medida durante os ensaios mecânicos. Com o sistema montado, infundiu-se a solução fisiológica contida no interior da seringa de plástico pré-posicionada no transdutor do polígrafo, preenchendo assim, o cateter de polietileno, a via lateral da torneira de tripla-via e o segmento de alça, pois o fluxo da torneira de tripla-via estava aberto nas três direções. Esse procedimento foi realizado para eliminar as bolhas de ar contidas dentro do sistema. Após, posicionando-se o fluxo da torneira de tripla-via na direção das vias lateral e inferior, o segmento de alça com as suas conexões eram transformadas em um sistema de vasos comunicantes em relação ao polígrafo. Depois dessas etapas, realizou-se um balanço no polígrafo, tomando essa posição como linha de base zero. Em seguida, tarou-se a balança e o movimento de tração era iniciado com a velocidade de $1 \mathrm{~cm} / \mathrm{min}$. A partir desse momento, originou-se um movimento de arrasto onde todos os componentes do sistema sofreram tração em direção vertical. Com isso, as forças axiais crescentes aplicadas sobre o segmento de alça transferiram-se para a célula de carga da balança de precisão. Esses valores eram capturados, registrados e analisados pelo microcomputador por meio do aplicativo SABI 2.0. A velocidade de aquisição da força axial externa imposta sobre o sistema apresentava a média de três dados por segundo e em tempo real, esses dados geravam uma curva na tela do computador expressando a função Força $\mathrm{x}$ Tempo. Com a finalização do processo de aquisição, essa função (Força x Tempo) era convertida, automaticamente, para a Função Força x Elongação por meio do aplicativo SABI 2.0. No instante de ruptura da alça, a força axial máxima foi denominada força de ruptura à tração (FT) e os dados adquiridos pós-rompimento não eram considerados no cálculo da ETR. Além disso, com a tração, ocorreu a formação de pressão dentro do sistema de vasos comunicantes, sendo essa pressão registrada pelo polígrafo. As variações da curva dessa pressão em relação ao tempo eram adquiridas e no momento de ruptura da alça cólica, a curva retornava a sua linha de base inicial zero decorrente da perda do líquido pelo ponto de rompimento da parede do espécime sob teste (Figura 5).

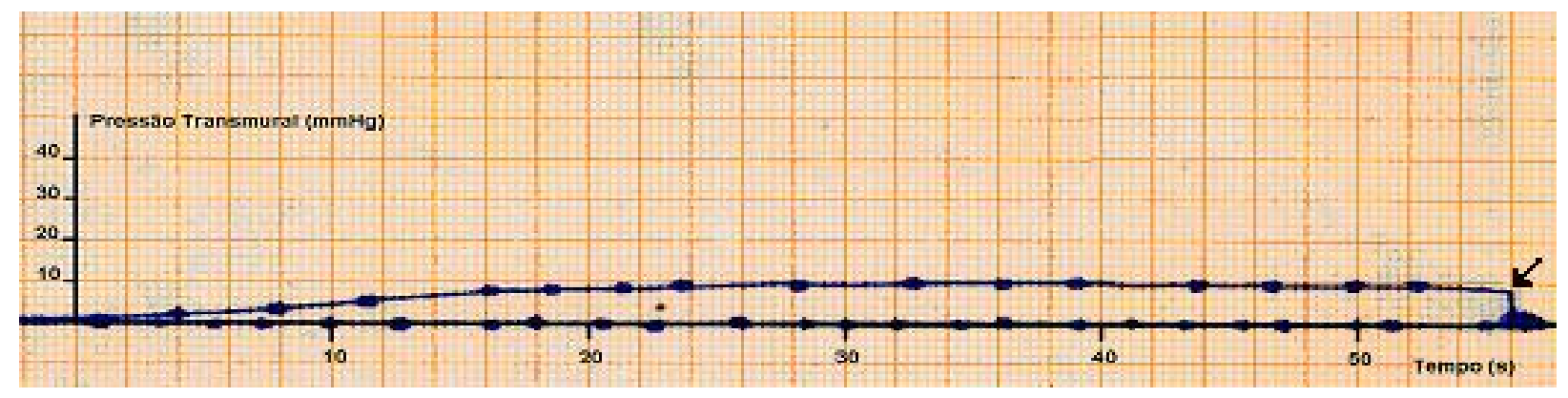

FIGURA 5 - Registro gráfico da função Pressão Transmural x Tempo gerado pelo polígrafo durante o teste ETR. A seta indica o momento exato de ruptura da alça intestinal

\section{Resultados}

As rupturas dos segmentos de alça cólica ocorreram, na totalidade, em região mediana dos espécimes. O teste biomecânico ETR, por meio do SABI 2.0, apresenta a capacidade de aquisição de dados de modo variável. Essa capacidade depende, exclusivamente, das características da balança de precisão na qual a célula de carga está inserida. 
Neste trabalho, o dispositivo de carga foi capaz de enviar uma média de três dados por segundo. Com essa velocidade de emissão e aquisição, o SABI 2.0 delineou de modo eficiente, as funções Força x Elongação necessárias para o cálculo da ETR (Figura 6).

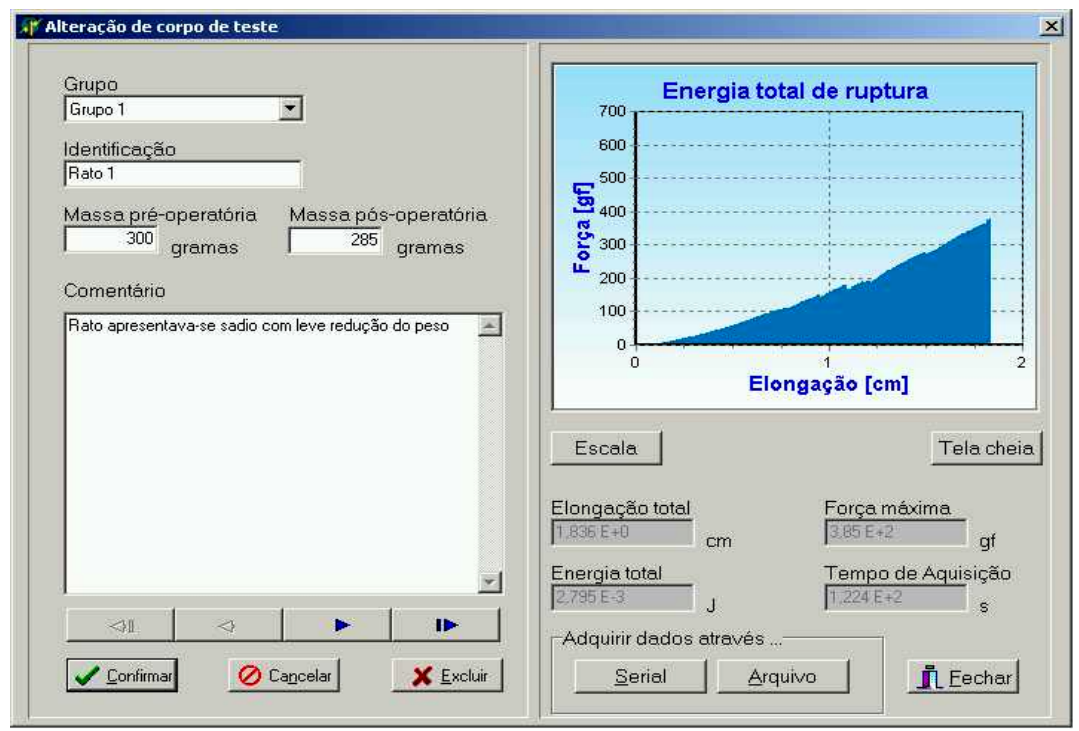

FIGURA 6 - Função Força x Elongação e atributos obtidos pelo SABI 2.0

Além da aquisição e análise dos dados, o SABI 2.0 foi implementado considerando-se outras funções computacionais. Uma dessas funcionalidades está relacionada à segurança do sistema, a qual é garantida pelo acesso restrito aos dados de cada usuário cadastrado, identificado pelo nome e senha. $\mathrm{O}$ sistema permite ainda a geração de relatórios e gráficos que descrevem, em vários níveis de detalhes, todas as informações relacionadas aos grupos, subgrupos e corpos de teste (Figura 7).

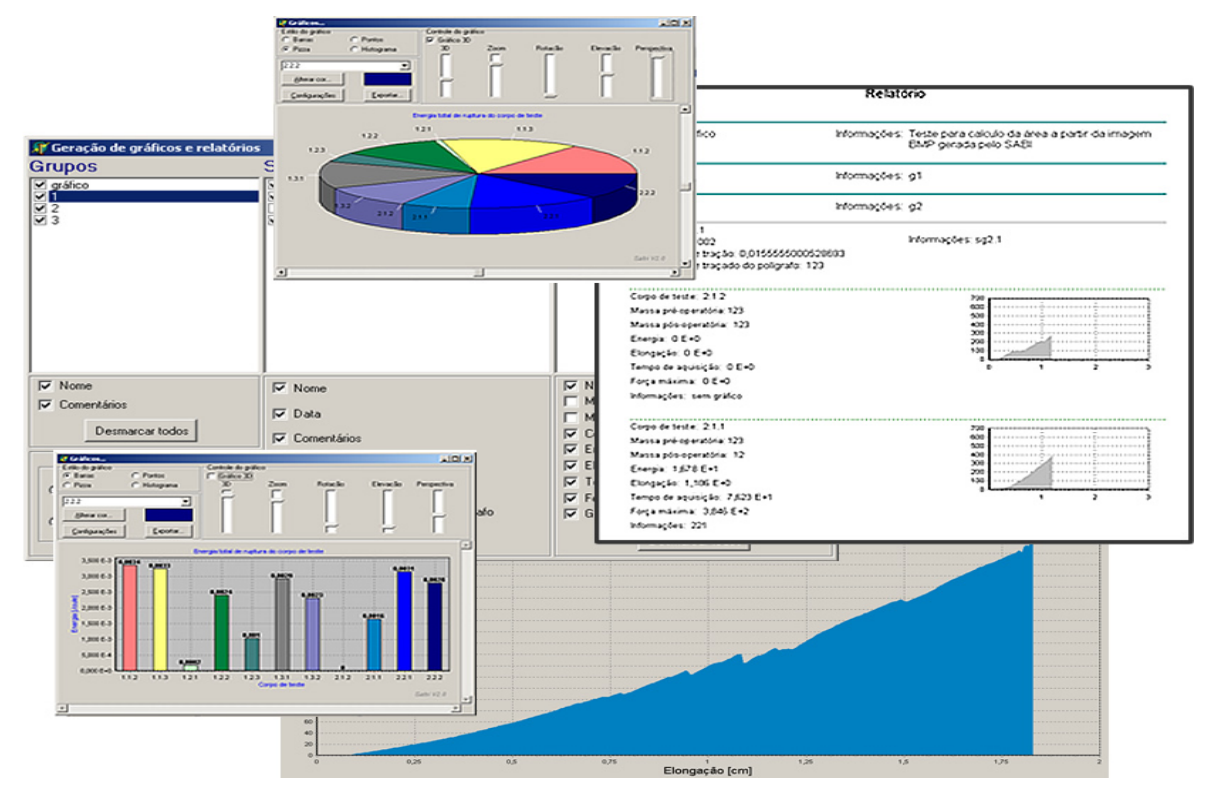

FIGURA 7 - Relatórios e gráficos gerados pelo SABI 2.0 
Essas informações podem ser armazenadas em forma de arquivos e inseridas em aplicativos para a realização de testes estatísticos. Para que pudessem ser realizados os testes desse sistema computacional, utilizaram-se 15 corpos de provas (segmento de cólon descendente de ratos).
Os valores obtidos por meio do teste biomecânico ETR estão distribuídos conforme a Tabela 1 enquanto os valores da média, do desvio-padrão, do erro-padrão e dos valores máximo e mínimo estão representados na Tabela 2.

TABELA 1 - Valores da Energia Total de Ruptura (ETR x 102) dos espécimes

\begin{tabular}{|c|c|c|c|c|c|c|c|c|c|c|c|c|c|c|c|}
\hline Rato & $\mathbf{1}$ & $\mathbf{2}$ & $\mathbf{3}$ & $\mathbf{4}$ & $\mathbf{5}$ & $\mathbf{6}$ & $\mathbf{7}$ & $\mathbf{8}$ & $\mathbf{9}$ & $\mathbf{1 0}$ & $\mathbf{1 1}$ & $\mathbf{1 2}$ & $\mathbf{1 3}$ & $\mathbf{1 4}$ & $\mathbf{1 5}$ \\
\hline ETR & 2,80 & 3,26 & 3,46 & 2,94 & 2,55 & 2,22 & 2,88 & 2,50 & 2,72 & 2,32 & 3,36 & 3,36 & 3,25 & 2,52 & 3,59 \\
\hline
\end{tabular}

TABELA 2 - Valores da média, do desvio-padrão, do erro-padrão, dos valores máximo e mínimo obtidos dos 15 espécimes submetidos aos ensaios biomecânicos ETR

\begin{tabular}{|c|c|c|c|c|c|}
\hline & média & desvio-padrão & erro-padrão & máximo & mínimo \\
\hline ETR & 292,96 & 43,97 & 11,35 & 359,5 & 221,9 \\
\hline
\end{tabular}

\section{Discussão}

Diversos parâmetros e modelos experimentais foram desenvolvidos com a finalidade de avaliar as propriedades físico-mecânicas apresentadas pelo tecido intestinal. Esses testes biomecânicos apresentam-se, freqüentemente, com características uniaxial e biaxial ${ }^{3,4}$.

Independentemente do método aplicado, todos os testes são passíveis de críticas. Sendo assim, uma das características primordiais durante o desenvolvimento de um modelo experimental é tentar minimizar as variáveis que possam interferir na obtenção de resultados mais precisos e completos.

Neste trabalho, propôs-se o teste biomecânico ETR com o intuito de medir a resistência intrínseca do cólon de ratos. Esse teste permitiu a reprodução matemática do comportamento físico-mecânico desse segmento de intestino após a imposição de uma força axial externa de tração e variável com o tempo.

Durante o desenvolvimento do teste biomecânico Energia Total de Ruptura, alguns conceitos e dispositivos foram modificados com o objetivo de minimizar variáveis que poderiam interferir na precisão dos resultados. Um dos aspectos analisados foi a maneira de fixação das extremidades da alça intestinal no sistema de tração.

Os espécimes são, freqüentemente, presos em sistema de tração por meio de garras ou prensas universais. Esses dispositivos são capazes de danificar a estrutura da parede do intestino. Além disso, quando as prensas não são posicionadas paralelamente em relação à linha de sutura, há distribuição desigual da força aplicada sobre os pontos pertencentes à essa área de secção transversal do espécime ${ }^{3,4,7}$. Para contornar esses efeitos indesejáveis, no teste biomecânico ETR, as extremidades dos segmentos de cólon foram amarradas em canhões de cateter $\mathrm{n}^{\mathrm{o}} 18$, respeitando a sua morfologia cilíndrica. Antes dos testes serem iniciados, preencheram-se os componentes pertencentes ao sistema com solução fisiológica. Por meio desse procedimento, a morfologia tubular da alça foi preservada durante a tração e a pressão gerada no interior desse sistema de vasos comunicantes distribuiu-se de forma homogênea, como rege o Princípio de Pascal. Além disso, a presença desse líquido dentro do sistema permite identificar, com exatidão, o momento de ruptura da parede do segmento de alça, pois o gráfico da pressão gerado pelo polígrafo durante o ensaio de tração, sofre queda abrupta no instante do rompimento ${ }^{4,7}$.

Os testes biomecânicos mais usados são representados por ensaios uniaxiais ${ }^{10}$ e biaxiais $^{4}$ para a verificação da resistência mecânica da linha anastomótica ou da parede íntegra de segmento intestinal. Desse modo, o comportamento físicomecânico da alça é analisado parcialmente e atributos essenciais pertencentes aos materiais viscoelásticos, tais como deformação, tempo de ruptura e módulo de elasticidade não são considerados durante os ensaios.

Decorrente desses fatores, pesquisadores têm utilizado fundamentos da física para determinar de maneira mais detalhada, o comportamento e as propriedades dos materiais biológicos durante os ensaios biomecânicos. Para isso, era necessário avaliar a inter-relação dos componentes constituintes 
desses tecidos, e desse modo, obter as suas equações analíticas $2,7,11,12,13$.

A parede do cólon é uma estrutura biológica complexa constituída principalmente por água, matriz extracelular, tecidos de sustentação, vascular e muscular liso ${ }^{14}$. Dentre as camadas, a submucosa assume posição fundamental na resistência mecânica desse órgão e um dos fatores que contribui para isso é o arranjo tridimensional do colágeno encontrado nessa túnica. Essa distribuição apresenta-se com aspecto ondulado decorrente da disposição biaxial e longitudinal de $+30^{\circ}$ e $-30^{\circ}$ das fibras ${ }^{15}$. As unidades estruturais desses componentes interagem entre si por meio de ligações atômicas, moleculares, intermoleculares e intercelulares, para no final, originar a cito-arquitetura intestinal. Sendo assim, quando o segmento de alça é submetido à tração por meio de uma força axial externa variável com o tempo, em cada instante, essa força é distribuída para as unidades estruturais constituintes, incidindo nas respectivas interações bioquímicas. Com isso, a resistência intrínseca do espécime não poderia ser representada por uma ou outra força, mas sim, pela resultante das forças aplicadas por unidade de tempo ou elongação. Essa grandeza equivale à energia total acumulada no espécime durante o ensaio mecânico até o momento de ruptura ${ }^{7}$. Testes biomecânicos baseados na Energia Interna de Deformação (EID) foram utilizados anteriormente por diversos pesquisadores e estão fundamentados no conceito da mecânica do meio contínuo e representados pelos modelos mecânicos como Modelos Analógicos de Maxwell e de Kelvin $^{2,12,13}$. Nesses trabalhos, a energia era calculada dentro do intervalo elástico da função Força x Deformação ou Tensão $\mathrm{x}$ Deformação ${ }^{2,11}$. Esse intervalo corresponde à distância entre o ponto inicial da curva da função até o limite de proporcionalidade ${ }^{16}$. Com isso, a avaliação do material biológico era realizada parcialmente, pois o comportamento adquirido pelo espécime após o limite de proporcionalidade até o momento de ruptura não era analisado.

$\mathrm{Na}$ prática cirúrgica em coloproctologia, as maiores complicações operatórias são decorrentes da quebra de integridade da parede ou da linha de sutura, proporcionando assim, o extravasamento do conteúdo fecal. Sob essa premissa, acredita-se que a Energia Total de Ruptura obtida por meio do teste biomecânico ETR representaria, provavelmente, de modo mais adequado o comportamento real e integral da resistência mecânica do segmento de cólon sob teste, já que a análise da função Força x Elongação foi realizada até o momento exato de ruptura ${ }^{7}$. A Energia Interna de Deformação é obtida por meio da área delimitada pela curva da função Tensão x Deformação. No entanto, para determinar o atributo tensão, é necessário o cálculo da área de secção transversal do cólon no instante de seu rompimento ${ }^{2,3}$.

A obtenção exata desse valor é extremamente difícil, pois as alças cólicas apresentam morfologia tubular e, a rigor, pertencem à classe de materiais com propriedade viscoelástica não-linear ${ }^{17}$. Além disso, quando o segmento de intestino é submetido à imposição de uma força axial externa de tração, origina-se um fenômeno denominado "fenômeno de constrição", ou seja, o diâmetro do segmento de alça e a parede na região mediana desse espécime sofrem estreitamento, alterando assim, o valor da área a cada instante de aplicação da força ${ }^{7,16}$. Desse modo, acredita-se que a constante de elasticidade do espécime também se modifica com a ação dessa força axial, pois a cada momento de tração, micro-rupturas e alterações da disposição celular e fibrilar ocorrem na estrutura da parede intestinal.

Outra análise realizada neste trabalho foi a avaliação da deformação sofrida pelo espécime após a aplicação da força axial externa. Esse atributo é definido como alongamento do corpo de prova por unidade de comprimento ${ }^{16}$.

A deformação é utilizada, amplamente, para compor o eixo das abscissas em ensaios de energia e apresenta-se com unidade adimensional e referida, freqüentemente, $\mathrm{em} \mathrm{cm} / \mathrm{cm}$, $\mathrm{mm} / \mathrm{mm}$ ou por meio de porcentagem ${ }^{16}$.

No método Energia Total de Ruptura, para compor a abscissa da função, empregou-se o atributo elongação (1) do segmento de cólon, substituindo assim, a deformação do material. Todos os espécimes iniciaram os testes com comprimentos iniciais $\left(l_{0}\right)$ de um e meio centímetros. Desse modo, por meio do aplicativo SABI 2.0, os valores da elongação foram capturados com média de três dados por segundo, do início do ensaio mecânico até o momento de ruptura do segmento de alça ${ }^{9}$. Nesse instante, definiu-se o atributo elongação final.

O comportamento biomecânico da alça intestinal está diretamente relacionado ao fator tempo em virtude desse material biológico possuir propriedade viscoelástica não-linear. Portanto, se a velocidade de tração para um mesmo espécime for modificada, energias resultantes obtidas serão diferentes ${ }^{2,16}$. Em razão disso, os espécimes desse trabalho foram submetidos aos ensaios ETR com velocidade de tração axial constante.

Sendo assim, respeitando as propriedades inerentes à estrutura intestinal e fundamentado nos conceitos físicos, biomecânicos e computacionais, concebeu-se o teste biomecânico ETR. Quando uma força axial externa é aplicada sobre o espécime, a energia empregada realiza um trabalho que se iguala à energia interna acumulada, adicionada às perdas energéticas oriundas do atrito, da temperatura, do som e da luz. No entanto, essas perdas energéticas já estão inseridas no cálculo da ETR, pois a força externa variável imposta pelo sistema de tração apresenta-se como força resultante ${ }^{7}$. Desse modo, o trabalho realizado para promover o rompimento do segmento de cólon descendente de rato, por meio da aplicação de uma força axial externa, é equivalente à Energia Total de Ruptura acumulada nesse espécime durante o ensaio mecânico, e pode ser representada pela equação abaixo:

$\mathrm{ETR}=? \int_{10}^{1} \mathrm{~F}(\mathrm{x}) \cdot \mathrm{dx}$

onde 1 = elongação final, $1_{0}=$ comprimento inicial,

$\mathrm{F}=$ força correspondente à elongação $1 \mathrm{e}$

$\mathrm{x}=$ elongação que varia de $1_{0}$ a 1 .

\section{Conclusão}

Por meio dos ensaios mecânicos e fundamentado em conceitos físico-mecânicos e computacionais, o teste Energia Total de Ruptura analisou, matematicamente, o comportamento 
dos segmentos de cólon descendente de ratos. Com isso, este teste biomecânico demonstrou ser um método de medição que poderá pertencer ao grupo de testes mecânicos cuja finalidade é avaliar a resistência intrínseca da parede intestinal e de anastomoses experimentais.

\section{Referências}

1. Fagundes JJ. Estudo comparativo da cicatrização de anastomoses cólicas realizadas com auxílio do bisturi elétrico e bisturi laser de dióxido de carbono: trabalho experimental em cães [Tese Doutorado]. Universidade Estadual de Campinas - Faculdade de Ciências Médicas; 1990.

2. Nieri TM. Estudo sobre o comportamento mecânico do cólon íntegro e com anastomose. Trabalho experimental em ratos [Dissertação Mestrado]. Universidade Estadual de Campinas - Faculdade de Ciências Médicas; 1999.

3. Hendricks T, Mastboom WJB. Healing of experimental intestinal anastomosis: parameters for repairs. Dis. Colon Rectum 1990; 33: 891-901.

4. Wu FC. Estudo da ação de aderências sobre anastomose cólica: trabalho experimental em ratos. [Dissertação - Mestrado]. Universidade Estadual de Campinas - Faculdade de Ciências Médicas; 2000.

5. Wu FC, Ayrizono MLS, Fagundes JJ, Coy CSR, Góes JRN, Leonardi LS. Estudos biomecânicos da ação de aderências sobre anastomose cólica. Trabalho experimental em ratos. Acta Cir Bras 2003; 18(3):216-223.

6. Gottrup F. Healing of incisional wounds in stomach and duodenum. A biomechanical study. Am J Surg 1980;140: 296-301.

7. Wu FC. Estudo dos efeitos de diferentes concentrações de oxigênio e da hiperoxigenação hiperbárica sobre anastomoses cólicas comprometidas ou não pela isquemia: trabalho experimental em ratos [Tese - Doutorado]. Universidade Estadual de Campinas Faculdade de Ciências Médicas; 2003.
8. Swokowski EW. Cálculo com geometria analítica. 2 ed. São Paulo: Makron Books; 1994.

9. Voltolini RF, Metz J, Machado RB, Lee, HD, Wu FC, Fagundes JJ, Góes JRN. SABI 2.0: Um sistema para a realização de testes biomecânicos em material viscoelástico não- linear. In: Torres GL, Abe JM, Mucheroni ML, Cruvinel PE. Advances in intelligent systems and robotics: Proceedings of the 4th Congress of logic Applied to Technology - Laptec 2003, 1 ed, São Paulo: Plêiade 2003, p. 93-9.

10. Souza Filho ZA, Ioshii SO, Greca FH, Biondo-Simões, MLP, Rocha SL, Duda JR, Oliveira Filho HR. Emprego da submucosa de intestino delgado porcina no reparo de lesões do esôfago cervical. Estudo experimental em cães. Acta Cir Bras 2003;18(3): 224-31.

11. Forrester JC. Mechanical, biochemical, and architectural features of surgical repair. Adv Biol Med Phys 1973;14:1-34.

12. Lanir Y. Constitutive equations for fibrous connective tissues. J Biomechanics 1983;16(1):1-12.

13. Fung YC. Biomechanics - Mechanical properties of soft living tissues. 2 ed. New York: Spring-Verlag Inc; 1993.

14. Witte MB, Barbul A. General principles of wound healing. Surg Clin North Am 1997;77(3):509-28.

15. Osberg JW, Klein L, Hiltner A. Scanning electron microscopy of collagen fibers in intestine. Conn Tiss Res 1982;9:187-93.

16. Popov EP. Introduction to mechanics of solids. 1 ed. New Jersey: Prentice-Hall Inc; 1968.

17. Dal Fabro IM. Strain failure of apple material [Tese - Doutorado]. Michigan State University; 1979.

\section{Agradecimentos}

Agradecemos aos Biólogos do Núcleo de Medicina e Cirurgia Experimental da Unicamp, Ana Cristina de Moraes e William Adalberto Silva. Agradecemos também ao Laboratório de Bioinformática da UNIOESTE e Instituto de Tecnologia em Automação e Informática pelo apoio técnico e CAPES, como agência financiadora.
Correspondência:

Feng Chung $\mathrm{Wu}$

LABI - Unioeste/Campus de Foz do Iguaçu

Avenida Tarqüínio Joslin dos Santos, 1300

85870-900 Caixa Postal: 961

Pólo Universitário Foz do Iguaçu - PR

wufc@ig.com.br
Conflito de interesse: nenhum

Fonte de financiamento: CAPES - Coordenação de Apoio à Pesquisa e Ensino Superior
Recebimento: 05/08/2004

Revisão: 10/09/2004

Aprovação: 16/10/2004

\section{Como citar este artigo:}

Wu FC, Lee HD, Machado RB, Dalmás S, Coy CSR, Góes JRN, Fagundes JJ. Apresentação do teste energia total de ruptura para avaliação de material biológico com propriedade viscoelástico não-linear. Acta Cir Bras [serial online] 2004 Nov-Dez;19(6). Disponível em URL: http://www.scielo.br/acb [também em CD-ROM].

*Figuras coloridas disponíveis em www.scielo.br/acb 